\title{
Root Cause of Analysis of Peculiar Response of Pneumothorax to Chest Tube Drainage
}

\author{
Szeto Ching Ho \\ Department of Tuberculosis and Chest, Wong Tai Sin Hospital, Hong Kong, China
}

Copyright (C) 2015 by authors, all rights reserved. Authors agree that this article remains permanently open access under the terms of the Creative Commons Attribution License 4.0 International License

\begin{abstract}
Chest tube drainage is a simple system to manage pneumothorax. It is inserted at the safety triangle after local anesthesia. Due to the positive intrapulmonary pressure and the negative intrapleural pressure during inspiration, air in the pleural space will be forced out into the chest drain bottle with underwater seal. The resorption of pneumothorax is further enhanced by oxygen therapy, which displaces the nitrogen inside the pneumothorax. Out of our expectation, there are cases with peculiar response to chest tube drainage. We should consider the following in the root cause analysis. 1. Chest drain system integrity: The chest drain should be placed in the pleural cavity, rather than sub-cutaneous or intra-abdominal cavity. The tubing should not be kinked or disconnected and the connection site should not be masked by dressing. 2. Anatomy of the pneumothorax: The anatomy of the pneumothorax should be on CXR or preferably contrast CT thorax. Any loculation, endobronchial obstruction, trapped lung due to old inflammatory process, lung entrapment due to persistent active inflammatory process should be noted. 3. Clinical assessment: It includes pleural fluid analysis, if present, and pleural manometry with air aspiration. In case of persistent air-leak seen in the chest drain bottle, suspect alveolopleural or bronchopleural fistula especially when patient is on positive pressure ventilation. Alternating or persistent bilateral pneumothorax without air-leak suggests interpleural communication (Simultaneous Bilateral Spontaneous Pneumothorax). The observed phenomena can be explained by considering the pressure change between various intra-thoracic compartments accounts for the observed phenomena, although confirmation of the communication during thoracoscopy is preferred.
\end{abstract}

Keywords Root Cause Analysis (RCA), Unresolved Pneumothorax, Chest Drain, Loculated Pneumothorax, Trapped Lung, Lung Entrapment, Simultaneous Bilateral Spontaneous Pneumothorax (SBSP), Alveolo-pleural and Broncho-pleural Fistula

\section{Introduction}

Root cause analysis can solve the problem of unresolved pneumothorax despite chest tube drainage. Removal of the root cause from the sequence of events prevents the final undesirable effect from recurring ${ }^{1}$.

\section{Materials and Methods}

During the period Jan 1, 2011 to July 31, 2015, 14450 episodes of pneumothorax were reported across hospitals in Hong Kong as recorded in the Clinical Data Analysis and Reporting System (CDARS) using ICD-9 coding. The data comes from 42 public hospitals and institutions, 47 specialist outpatient clinics and 73 general outpatient clinics. These are organised into 7 hospital clusters based on location. Although the CDARS system is powerful, the incorrect disease entry by individual doctor may make the interpretation difficult. Having said that, we can observe the general trend of disease prevalence and the treatment received. For example, simple pneumothorax will be treated by observation with oxygen therapy. Some cases are treated with chest drain only. More difficult cases may require talc pleurodesis to prevent recurrence. Patients on mechanical ventilation or requiring surgical thoracoscopy reflect the portion of 'difficult pneumothorax'. By investigating each step from the chest drain insertion, daily monitoring, application of suction, pleurodesis, up to the removal of chest drain, we can identify the root cause of 'difficult pneumothorax'.

\section{Results}

Out of the 14450 patients with pneumothorax, 5554 (38.4\% of total) patients required chest drain insertion. Most patients (91\% of total) suffered from spontaneous pneumothorax and only $3.3 \%$ of total patients had spontaneous tension pneumothorax. $5.8 \%$ patients acquired 
pneumothorax during medical precedure. 1418 patients (9.8\% of total) required surgical intervention and pleurodesis.

1185 patients (8.2\% of total) with pneumothorax were put on positive pressure mechanical ventilation for one reason or the other. They were prone to develop bronchopleural fistula. Some patients with 'difficult pneumothorax' have poor general condition and cannot tolerate the general anaesthesia and surgical intervention. Although this portion of patients is small, treatment is still available.

39 patients $(0.27 \%)$ with empyema thoracis developed fistula leading to hydropneumothorax. There were 581 cases of tuberculous pleural effusion (23 cases has lung cavity) requiring chest tube drainage but, interestingly, there was no documented tuberculous pneumothorax in the past 4.5 years.

Ultrasound thorax (135 patients, 0.93\%) was less commonly used in pneumothorax as compared to CT thorax (825 patients, 5.7\%) due to the inferior sensitivity in detecting small pneumothorax, and 'relatively' less information obtained.

Patients with pneumothorax and trapped lung (13 patients, $0.09 \%$ ) were much less common than those with pneumothorax and lung entrapment (406 patients, 2.8\%).
Pneumothorax was also found in patients with lymphangiitis carcinomatosis (112 patients, 0.77\%), endobronchial tumor obstruction (28 patients, $0.2 \%$ ), and restrictive lung disease (23 patients, $0.16 \%$ ).

Lung secondaries causing pneumothorax (1113 patients, 7.7\%) were relatively not rare especially those with bone osteosarcoma. Contrary to most people's belief, pneumothorax in COPD patients (197 patients, 1.4\%) or in asthma patients (181 patients, $1.3 \%$ ) were not many. Rare causes of pneumothorax like tuberous sclerosis only accounted for 3 patients $(0.02 \%$ of total).

By looking through each step of chest tube drainage in managing patients with pneumothorax, we can solve most of the problems of 'difficult pneumothorax'. Literature review shows most of the time, it is due to incorrect chest drain insertion and subsequent daily monitoring. Although referral to thoracic surgeon is a good solution to 'difficult pneumothorax', sometimes it is difficult for patients with other comorbidities or having poor anaesthetic risk. At that situation, pleural fluid analysis, pleural space manometry, contrast CT thorax, and subsequent bronchoscopic endobronchial valve insertion may solve the problem.

Table 1. Root Cause Analysis to Peculiar Response of Pneumothorax to Chest Drainage

\begin{tabular}{|c|c|c|c|c|c|}
\hline Level of analysis & Questions & Findings & Root Cause & Ask why? & Take action \\
\hline $\begin{array}{l}\text { What happened ? } \\
\text { Unresolved } \\
\text { pneumothorax }\end{array}$ & $\begin{array}{l}\text { Failure of lung } \\
\text { re-expansion or } \\
\text { persistent air-leak } \\
\text { after 5-7 days of chest } \\
\text { tube drainage } \\
\text { - What areas are } \\
\text { impacted? Prolong } \\
\text { hospitalization and } \\
\text { increase secondary } \\
\text { complications }\end{array}$ & $\begin{array}{l}\text { - Increase cost } \\
\text { of } \\
\text { hospitalization } \\
\text { - Increase } \\
\text { mortality }\end{array}$ & $\begin{array}{l}\text { Do not follow } \\
\text { chest drain } \\
\text { protocol } \\
\text { Patient is unfit } \\
\text { for surgery. }\end{array}$ & $\begin{array}{l}\text { - Clumsy guideline and } \\
\text { protocol } \\
\text { - Comorbidities making patient } \\
\text { unsuitable for general } \\
\text { anesthesia and surgery }\end{array}$ & $\begin{array}{l}\text { - Simplify the } \\
\text { protocol } \\
\text { - Employ medical } \\
\text { advancement } \\
\text { like } \\
\text { endobronchial } \\
\text { valve insertion }\end{array}$ \\
\hline $\begin{array}{l}\text { Why does it } \\
\text { happen? }\end{array}$ & $\begin{array}{l}\text { Steps in the process } \\
\text { - Chest drain } \\
\text { insertion+/- suction } \\
\text { - underlying lung } \\
\text { pathology }\end{array}$ & $\begin{array}{l}\text { - malposition of } \\
\text { chest drain or } \\
\text { connection } \\
\text { problem } \\
\text { - lung pathology } \\
\text { not yet } \\
\text { corrected }\end{array}$ & $\begin{array}{l}\text { - Not inserting } \\
\text { chest drain } \\
\text { correctly, not } \\
\text { checking } \\
\text { connection and } \\
\text { tube kinking } \\
\text { daily } \\
\text { - Not performing } \\
\text { thorax imaging } \\
\text { and pleural } \\
\text { manometry } \\
\text { - Not considering } \\
\text { the pressure } \\
\text { profile }\end{array}$ & $\begin{array}{l}\text { incorrect position of chest } \\
\text { drain, tube kinking, loculated } \\
\text { pneumothorax, endobronchial } \\
\text { obstruction, trapped lung and } \\
\text { lung entrapment, interpleural } \\
\text { communication in SBSP. } \\
\text { alveolopleural/ } \\
\text { bronchopleural fistula } \\
\text { especially when patient is on } \\
\text { positive pressure ventilation }\end{array}$ & $\begin{array}{l}\text { Daily check the } \\
\text { chest drain system } \\
\text { integrity } \\
\text { - Learn bedside } \\
\text { US and ask for } \\
\text { CT thorax } \\
\text { - perform pleural } \\
\text { manometry with } \\
\text { air aspiration } \\
\text { - Think of } \\
\text { pressure change } \\
\text { especially in } \\
\text { SBSP }\end{array}$ \\
\hline $\begin{array}{l}\text { What are the } \\
\text { most proximate } \\
\text { factors? }\end{array}$ & $\begin{array}{l}\text { - Human factors } \\
\text { - Equipment } \\
\text { factors }\end{array}$ & $\begin{array}{l}\text { - Inadequate } \\
\text { thoracic } \\
\text { surgical } \\
\text { service } \\
\text { - Inadequate } \\
\text { imaging } \\
\text { facilities }\end{array}$ & $\begin{array}{l}\text { Thoracic } \\
\text { surgery not } \\
\text { available in } \\
\text { primary } \\
\text { hospital } \\
\text { Waiting time } \\
\text { for CT thorax is } \\
1-2 \text { months }\end{array}$ & $\begin{array}{l}\text { High cost of setting a thoracic } \\
\text { surgical unit in every hospital } \\
\text { - Lots of people waiting for CT } \\
\text { thorax }\end{array}$ & $\begin{array}{l}\text { chest drain } \\
\text { manipulation, } \\
\text { interventional } \\
\text { pulmonology } \\
\text { make use of } \\
\text { pleural } \\
\text { manometry }\end{array}$ \\
\hline
\end{tabular}

(US: ultrasound, CT: computerized tomography, SBSP: simultaneous bilateral spontaneous pneumothorax) 
It seems that chest drain insertion through the safe triangle after local anesthesia is simple. However, less than $50 \%$ junior doctors could mark the safe triangle correctly for chest drain insertion ${ }^{2}$. If the chest drain is in the correct position, there should be swinging of the water column during patient's respiration and the gush of air coming out during patient's coughing. There should be no kinking of the chest drain and the connection between the chest drain and chest drain bottle should be checked daily. Nursing experiences in chest drain care vary as there is no consistent treatment regime and evidence -based nursing care ${ }^{3}$.

Thoracic ultrasound can identify minute pleural effusion, loculated pneumothorax, and thickened wall in empyema whereas CT thorax can identify endobronchial obstruction, mediastinal lymph nodes, trapped lung and lung entrapment, and possibly interpleural communication in 3-D reconstruction ${ }^{4,5}$.

Patient, with trapped lung or lung entrapment, usually presents with pleural effusion. During chest tapping, the effusion cannot be completely drained due to chest pain ${ }^{6}$. And in fact, unexpandable lung is the most common cause of pneumothorax after chest tapping ${ }^{7}$. When you drain the fluid, air goes in the thoracic cavity due to the negative pressure you produced during fluid aspiration.

Lung entrapment is due to persistent active inflammation causing effusion and pleural restriction whereas trapped lung is due to old inflammation resulting in fibrous layer in pleural space. The acute phenomeon of lung entrapment is seen in inflammatory visceral pleura encasing a lung segment, or it can be due to increased elastic recoil in lymphangiitis carcinomatosa, or due to endobronchial obstruction leading to lung collapse. Trapped lung is seen after infection, hemothorax, rheumatoid or uraemic pleuritis, and cardiac surgery. Analysis of pleural fluid showed lymphocytic exudate in lung entrapment and transudate in trapped lung ${ }^{8}$.

Normally the pleural pressure at functional residual capacity is -3 to $-5 \mathrm{cmH}_{2} \mathrm{O}$. In lung entrapment, the pleural pressure, initially positive, falls gradually until more than 1.5-2L is draining out. At that time, the pleural pressure drops rapidly. Pulmonary elastance (Pel) is higher than 20 $\mathrm{cmH}_{2} \mathrm{O} / \mathrm{L}$. In trapped lung, the pleural pressure drops steeply from the start of chest tapping with Pel more than 25 $\mathrm{cmH}_{2} \mathrm{O} / \mathrm{L}$. Treatment varies according to the underlying cause, like laser recanalization and stenting in case of malignant endobronchial obstruction, and surgical decortication for trapped lung due to empyema thoracis.

Alveolopleural fistula presents with persistent air leak after the development of communication between the lung parenchyma distal to segmental bronchus and the pleural space. Bronchopleural fistula communicates segmental bronchi and the pleural space. Patient gets hypoxia and finally requires mechanical ventilation. We aim at using low tidal volume, low PEEP (positive end-expiratory pressure), less positive pressure breaths to promote fistula healing. Suction through the chest drain is discontinued ${ }^{9}$. We can connect the underwater seal to the inspiratory limb of ventilator circuit causing intermittent inspiratory chest drain occlusion or connect the underwater seal to the expiratory limb of ventilator circuit to limit the air-leak during expiration. Other methods include independent lung ventilation, high frequency ventilation and closure of fistula by surgery or endobronchial valve insertion ${ }^{10-13}$.

Simultaneous bilateral spontaneous pneumothorax (SBSP) describes the occurrence of bilateral pneumothorax at the same instant of time. If the pleural spaces are separate, SBSP can be treated by bilateral chest tube drainage with suction followed by talc pleurodesis. When there is pleuro-pleural communication, the suctional forces applying to the two pleural spaces will cancel each other and the trans-pulmonary pressure cannot be reached the critical level to inflate the lungs. As the lung defect causing the pneumothorax is healed up in a week or so, there will be no air-leak seen in the chest drain bottle. The lungs act as one mass, being pulled to the left or the right leading to left or right pneumothorax, respectively. Finally, both lungs are not fully expanded. It can be corrected by surgical pleurodesis or ways to increase the intrapulmonary pressure followed by talc pleurodesis $^{14-15}$.

\section{Conclusions}

Two lungs and two pleural spaces work in harmony according to the pressure change. Chest tube drainage system, with or without suction, solves most cases of pneumothorax. To maintain a negative pleural pressure, we need an isolated pleural space, patent tubings, together with an expandable lung. Performing the root cause analysis of each step will solve the problem of peculier response of pneumothorax to chest drainage.

\section{REFERENCES}

[1] Root cause analysis- Wikipedia, the free encyclopedia.

[2] Elsayed H, Chest drain insertion is not a harmless procedure--are we doing it safely? Interact Cardiovasc Thorac Surg. 2010 Dec;11(6):748-9

[3] Lehwaldt, Daniela. Nurses' knowledge of chest drain care: an exploratory descriptive survey. Nursing in Critical Care; Jul/Aug2005, Vol. 10 Issue 4, p192-200, 9p.

[4] Ajit Moghekar. Thoracic ultrasound: Picture worth a thousand sounds. Annals of Thoracic Medicine (Impact Factor: 1.34). 01/2014; 9(4):185-186.

[5] H. Kalkan. Thoracic application of multidetector CT. European Society of Thoracic Imaging 2014 / P-0078

[6] Feller-Kopman D. The relationship of pleural pressure to symptom development during therapeutic thoracentesis. Chest. 2006; 129:1556-60.

[7] Heidecker J. Pathophysiology following ultrasound-guided thoracentesis. Chest. 2006; 130:1173-84. 
[8] Marco F. Unexpandable Lung. Arch Bronconeumol. 2013;49:63-9. - Vol. 49 Num.02

[9] Pierson DJ. Persistent bronchopleural air leak during mechanical ventilation. Chest 1986; 90: 321-323

[10] Downs JB. Treatment of bronchopleural fistula during continuous positive pressure ventilation. Chest 1976; 69: 363-366

[11] Ha DV. High frequency oscillatory ventilation in the management of a high output bronchopleural fistula: a case report. Can J Anesth 2004; 51(1): 78-83
[12] Bishop MJ. Comparison of high-frequency jet ventilation with conventional mechanical ventilation for bronchopleural fistula. Anesth Analg 1987; 66: 833-838

[13] Toma TP. Reduction of persistent air leak with endobronchial valve implants. Thorax 2007; 62: 830-3

[14] Graf-Deuel E. Simultaneous bilateral spontaneous pneumothorax. Chest. 1994 Apr;105(4):1142-6.

[15] Yoshinobu Hata. Simultaneous bilateral spontaneous pneumothorax with congenital pleuro-pleural communication. J Thorac Dis. 2013 Feb; 5(1): 87-89. 